\title{
Resonant Raman study of local vibration modes in AlGaAsN layers
}

\author{
E. Gallardo , S. Lazić , J.M. Calleja , J. Miguel-Sánchez , M. Montes , A. Hierro , \\ R. Gargallo-Caballero, A. Guzmán , E. Muñoz , A.M. Teweldeberhan , S. Fahy \\ Dept. de Fisica de Materiales, Universidad Autónoma de Madrid, E-28049 Madrid, Spain \\ Instituto de Sistemas Optoelectrónicos y Microtecnología, Universidad Politécnica de Madrid, E-28040 Madrid, Spain \\ Tyndall National Institute, Lee Maltings, Prospect Row, Cork, Ireland \\ Isofoton, E-29590 Málaga, Spain
}

\begin{abstract}
We report on resonant inelastic light scattering in dilute $\mathrm{AlGaAsN}$ films. Intense narrow peaks associated to N-related local vibration modes (LVM) have been observed around $325,385,400,450,500$ and $540 \mathrm{~cm}^{-1}$. Their frequencies are compared to density functional theory supercell calculations of $\mathrm{Al}_{n} \mathrm{Ga}_{4-n} \mathrm{~N}$ complexes $(n=1-4)$. We find clear indications of the formation of $\mathrm{Al}_{4} \mathrm{~N}$ complexes. The values of the extended phonon frequencies reveal changes in the $\mathrm{N}$ distribution depending on the growth conditions. The LVM spectra are resonant in the energy range from 1.75 to $1.79 \mathrm{eV}$, which corresponds to an N-related electronic transition. Our results confirm the preferential bonding of $\mathrm{N}$ to $\mathrm{Al}$ in $\mathrm{AlGaAsN}$.
\end{abstract}

Keywords: AlGaAsN; Resonant Raman scattering; Local vibrational modes

\section{Introduction}

Pure GaAs and InGaAs alloys containing small concentrations of nitrogen have been of special interest in the last years for their applications in long-wavelength devices $[1,2]$ and for fundamental aspects of material physics. The addition of small amounts of nitrogen to these materials results in a strong reduction of the band gap energy also observed in AlGaAsN alloys The change in the optical properties depends on the details of the $\mathrm{N}$ incorporation to the lattice (preferential bonding, pair formation, etc.). Therefore, the study of the local bonding in diluted nitrides is essential for the understanding of these semiconductor alloys. Resonant Raman scattering (RRS) has been shown to be a useful technique to study the local vibration modes (LVM) associated to substitutional $\mathrm{N}$ in these diluted nitrides

In this paper we report experimental and theoretical results on the N-related LVM in AlGaAsN samples with different $\mathrm{N}$ concentrations. RRS measurements at low temperature show sharp LVM peaks at 325, 385, 400, 450, 500 and $540 \mathrm{~cm}^{-1}$. Calculations based on the density functional theory (DFT) suggest that they correspond to $\mathrm{Al}_{n} \mathrm{Ga}_{4-n} \mathrm{~N}$ complexes $(n=1-4)$. This is consistent with the known tendency of $\mathrm{N}$ to bond to $\mathrm{Al}$ atoms due to the higher $\mathrm{Al}-\mathrm{N}$ bond strength as compared to the $\mathrm{Ga}-\mathrm{N}$ bond

This bonding tendency depends strongly on the growth temperature.

\section{Experiment}

For the present study, $\mathrm{Al}_{0.22} \mathrm{Ga}_{0.78} \mathrm{As}_{1-y} \mathrm{~N}_{y}$ layers with $500 \mathrm{~nm}$ thickness were grown on $\mathrm{GaAs}$ substrates by molecular beam epitaxy using a radiofrequency plasma source for the supply of atomic nitrogen. A GaAs cap layer of $100 \mathrm{~nm}$ was grown on top of the samples. The substrate temperature was varied from 445 to $595^{\circ} \mathrm{C}$ for different samples, yielding $\mathrm{N}$ concentrations in the $\mathrm{AlGaAsN}$ layers up to $y=0.01$. An equivalent AlGaAs (nitrogen free) sample was grown as a reference. The $\mathrm{N}$ concentration was 
roughly estimated using X-ray diffraction, from the shift of the AlGaAsN layer diffraction peak with respect to that of $\mathrm{AlGaAs}$ in $\theta-2 \theta$ scans. Post-growth rapid thermal annealing was carried out in some samples.

RRS spectra were recorded in backscattering geometry at room and low temperature using Ti-sapphire and dye lasers as excitation sources and a double-grating spectrometer with a charged coupled device detector. A continuous flow cryostat with $\mathrm{He}$-exchange gas was used for low temperature $(77 \mathrm{~K})$ measurements.

\section{Theory}

DFT supercell calculations of the LVM frequencies and vibrational density of states have been performed for $\mathrm{Al}_{n} \mathrm{Ga}_{4-n} \mathrm{~N}$ clusters in $\mathrm{AlGaAsN}$ using a finite dynamical matrix approach, whereby harmonic restoring forces are found by small displacements of each atom from its equilibrium position.

\section{Results and discussion}

The Raman spectra at low temperature $(77 \mathrm{~K})$ of two samples with $\mathrm{N}$ concentrations of $0.1 \%$ and $1 \%$ are shown in Fig. 1. Besides the LO phonon of the GaAs substrate at $290 \mathrm{~cm}^{-1}$, extended GaAs-like $\left(\mathrm{LO}_{1}, \mathrm{TO}_{1}\right)$ and AlAs-like $\left(\mathrm{LO}_{2}, \mathrm{TO}_{2}\right)$ phonons of the ternary compound are observed. Second-order features appear in the 560$590 \mathrm{~cm}^{-1}$ region. In addition, the spectra show six peaks at frequencies around $325,385,400,450,500$ and $540 \mathrm{~cm}^{-1}$ (marked by arrows in Fig. 1), which are absent in $\mathrm{N}$-free samples. These modes, appearing only with the simultaneous presence of $\mathrm{Al}$ and $\mathrm{N}$, have already been observed in the past in room-temperature measurements However, they are much sharper and more intense in low temperature spectra They are interpreted as LVM of different $\mathrm{Al}_{n} \mathrm{Ga}_{4-n} \mathrm{~N}$ complexes. LVM frequencies and density of states have been calculated as described in Section 3. The results for "mainly" $\mathrm{Al}$ and $\mathrm{N}$ motion for $n=1$ and 2 are shown in Fig. 1. They are in fair qualitative agreement with the experimental data, where low-frequency modes are related to $\mathrm{Al}$ and high-frequency ones to $\mathrm{N}$ displacements. LVM at 385 and $400 \mathrm{~cm}^{-1}$ are the most intense features. The high intensity of the $400 \mathrm{~cm}^{-1}$ peak in the sample with nominally less $\mathrm{N}$ content is probably due to resonance effects. These intense modes are interpreted as due to $n=3$ and 4 complexes. Actually our DFT calculations indicate a singlet LVM at $410 \mathrm{~cm}^{-1}$ in $\mathrm{Al}_{4} \mathrm{~N}$ complexes (see Fig. 1). Although very scarce in a random ion distribution, $\mathrm{Al}_{4} \mathrm{~N}$ complexes may form with noticeable abundance due to the strong $\mathrm{Al}-\mathrm{N}$ binding energy (also confirmed by our DFT formation energy calculations). Upon rapid thermal annealing, the mode at $385 \mathrm{~cm}^{-1}$ grows while the one at $400 \mathrm{~cm}^{-1}$ loses intensity, thus revealing that the two modes originate from different complexes.

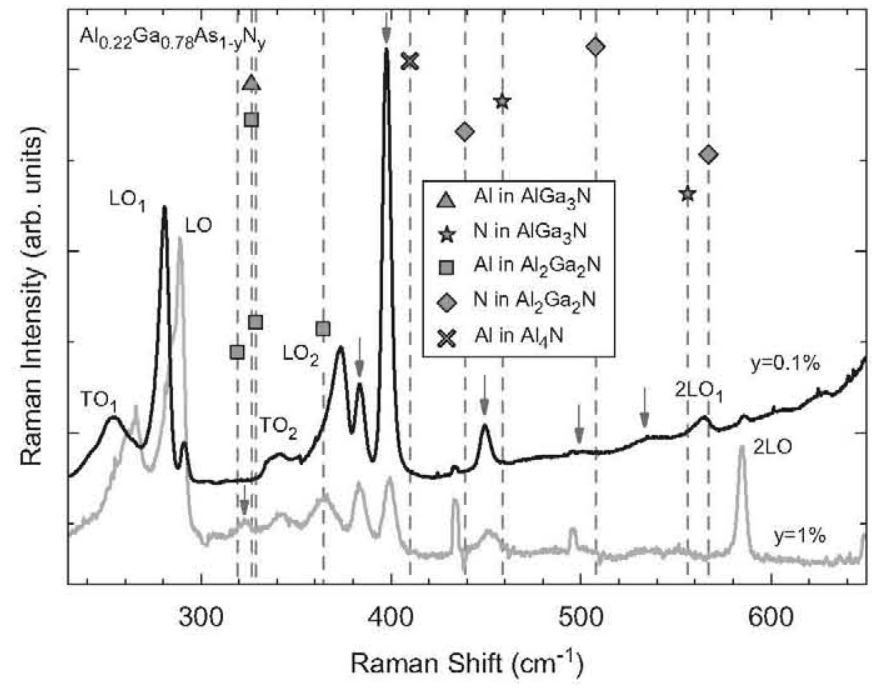

Fig. 1. Raman spectra at $77 \mathrm{~K}$ of dilute $\mathrm{AlGaAsN}$ films with $0.1 \%$ and $1 \%$ of $\mathrm{N}$ concentration. Experimental and theoretical LVM are marked by arrows and symbols (squares, triangles, diamonds, stars and crosses), respectively. Narrow peaks at 435 and $495 \mathrm{~cm}^{-1}$ are Ne spectral lines for calibration purposes.

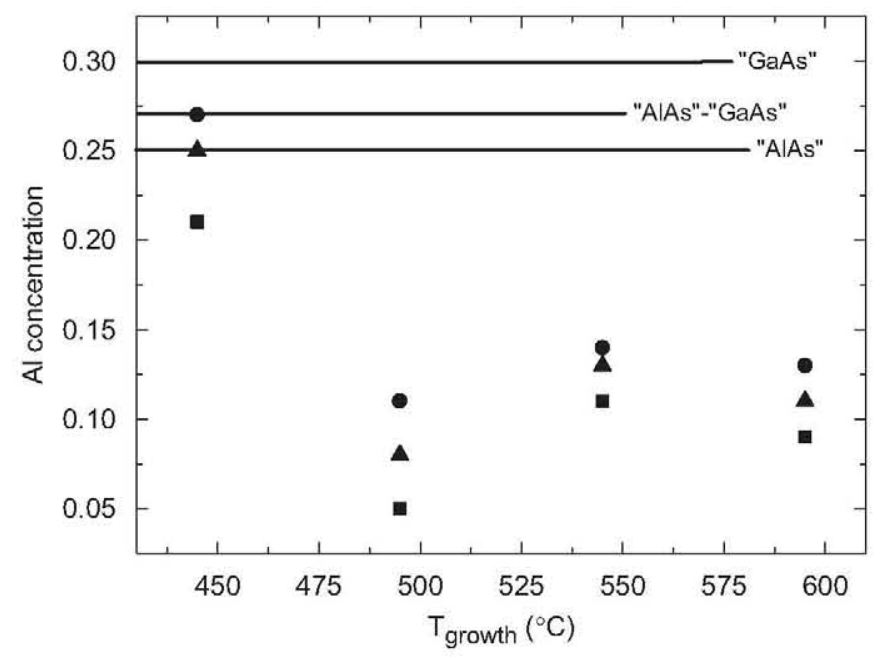

Fig. 2. Apparent $\mathrm{Al}$ concentration versus growth temperature for samples grown with equal growth parameters except temperature. The values represented with circles, squares and triangles have been calculated from the frequency of $\mathrm{LO}_{1}$ phonon, the frequency of the $\mathrm{LO}_{2}$ phonon and the difference of frequencies between them, respectively. The solid lines correspond to the experimental values for the samples without $\mathrm{N}$.

Apart from the appearance of LVM, the incorporation of nitrogen causes a low-frequency shift of the AlAs-like $\mathrm{LO}_{2}$ mode and a high-frequency shift of the GaAs-like $\mathrm{LO}_{1}$ phonon The intensity of the extended phonons is also affected by the addition of $\mathrm{N}$. These effects are due to the preferential formation of $\mathrm{Al}-\mathrm{N}$ bonds upon the addition of nitrogen, and the consequent reduction of $\mathrm{Al}-\mathrm{As}$ bonds The apparent concentration of $\mathrm{Al}$ (Al bonded only to As atoms) depends on the growth temperature, as shown in Fig. 2, for samples grown using the same radiofrequency power and nitrogen and aluminium fluxes. The $\mathrm{LO}_{1}$ 


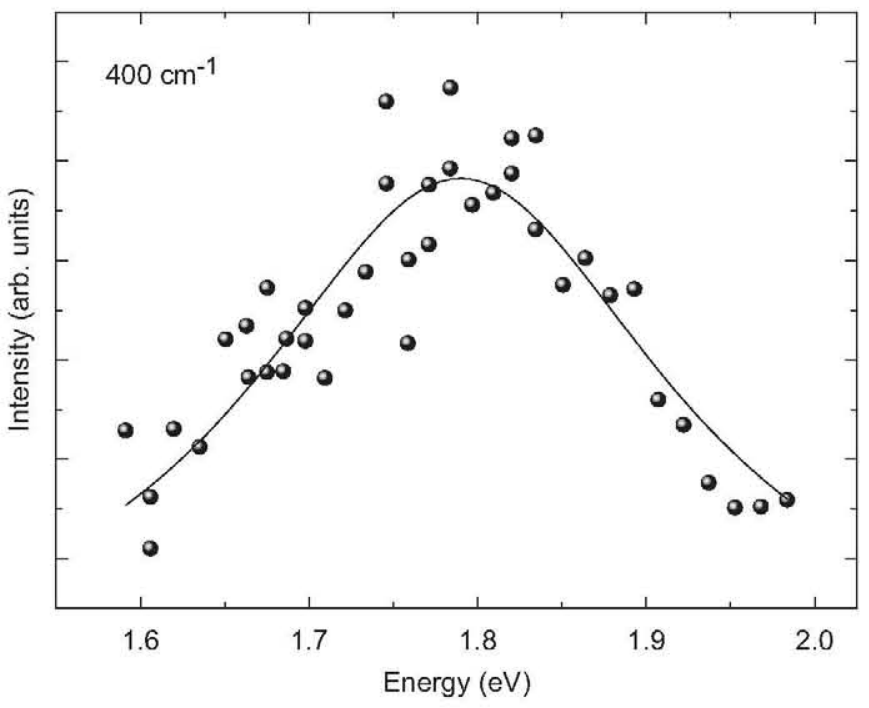

Fig. 3. Raman resonance at $77 \mathrm{~K}$ of the peak at $400 \mathrm{~cm}^{-1}$ for a sample containing $1 \%$ of $\mathrm{N}$.

frequencies (circles), the $\mathrm{LO}_{2}$ ones (squares) and the difference of frequency between them (triangles) show the same trend The significant decrease of the apparent $\mathrm{Al}$ concentration for growth temperatures above $450{ }^{\circ} \mathrm{C}$ reveals a transition from random to non-random nitrogen distribution. At $445^{\circ} \mathrm{C}$, the apparent $\mathrm{Al}$-content is lower but close to the experimental values for the samples without $\mathrm{N}$ (solid lines). At low growth temperatures, the atomic mobility is comparatively low, and the abundance of $\mathrm{Al}-\mathrm{N}$ bonds should be close to random. At higher growth temperatures the $\mathrm{Al}$ and $\mathrm{N}$ atoms have enough mobility to find each other forming $\mathrm{Al}-\mathrm{N}$ bonds, which are energetically more favourable. The $\mathrm{Al}-\mathrm{N}$ bond abundance should then increase and the apparent $\mathrm{Al}$ content should decrease, as observed. The mode at $400 \mathrm{~cm}^{-1}$ is not present in the sample grown at the lowest temperature, while the mode at $385 \mathrm{~cm}^{-1}$ is still present. This is an additional indication of the different origin of both LVM. According to the previous argument, the peak at $400 \mathrm{~cm}^{-1}$ should belong to clusters having more $\mathrm{Al}-\mathrm{N}$ bonds.

By changing the excitation energy in the range from 1.6 to $2 \mathrm{eV}$, the peak at $400 \mathrm{~cm}^{-1}$ of a sample with $1 \%$ of $\mathrm{N}$ concentration presents the resonance shown in Fig. 3, with a maximum at $1.78 \mathrm{eV}$. This value is above the band gap of our samples, which is $1.58 \mathrm{eV}$ at $77 \mathrm{~K}$ for the sample with the lowest $\mathrm{N}$ composition $(0.1 \%)$. Consequently, the resonance is not related to the energy gap of the dilute AlGaAsN. This was the assumption of Refs. $[9,10]$ where the gap of the ternary compound having $33 \% \mathrm{Al}$ composition is in the $1.8 \mathrm{eV}$ region. In fact, the similar value of the resonance energy in Refs. $[9,10]$ and the present work indicate that the LVM resonate with an electronic transition involving $\mathrm{N}$-related levels. The $\mathrm{E}_{+}$ transition , as due to the anticrossing between the extended states of the $\Gamma$ conduction band and the localized states of nitrogen, is a good candidate. Our result cannot rule out the alternative origin of an $\mathrm{N}$-induced interactions between extended $\Gamma, \mathrm{L}$, and $\mathrm{X}$ conduction-band states. In GaAs, this transition occurs around $1.7 \mathrm{eV}$ and we can expect that this value increases moderately upon incorporation of $20 \% \mathrm{Al}$.

\section{Conclusion}

RRS measurements in $\mathrm{Al}_{0.22} \mathrm{Ga}_{0.78} \mathrm{As}_{1-y} \mathrm{~N}_{y}$ films with different $\mathrm{N}$ concentrations have been performed. Shifts in the extended phonon frequencies reveal that the apparent $\mathrm{Al}$ content is changing with $\mathrm{N}$ incorporation and with growth temperature. Upon increasing the growth temperature from 445 to $495^{\circ} \mathrm{C}$, the $\mathrm{N}$ distribution changes from random to non-random. LVM attributed to different

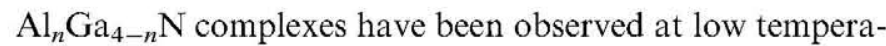
tures, including possibly $\mathrm{Al}_{4} \mathrm{~N}$ units. Their frequencies are in fair agreement with DFT calculations. The LVMs are resonant near $1.8 \mathrm{eV}$, independently of the $\mathrm{N}$ content. We suggest that this energy corresponds to the $\mathrm{N}$-related $\mathrm{E}_{+}$ transition.

\section{References}

M. Kondow, S. Nakatsuka, T. Kitatani, Y. Yazawa, M. Okai, Jpn. J. Appl. Phys. 35 (1996) 5711.

J.F. Geisz, D.J. Friedman, J.M. Olson, S.R. Kurtz, B.M. Keyes, J. Crystal Growth 195 (1998) 401.

M. Weyers, M. Sato, H. Ando, J. Appl. Phys. 31 (1992) L853.

J.D. Perkins, A. Mascarenhas, Y. Zhang, J.F. Geisz, D.J. Friedman, J.M. Olson, S.R. Kurtz, Phys. Rev. Lett. 82 (1999) 3312.

W. Shan, W. Walukiewicz, K.M. Yu, J.W. Ager, E.E. Haller, J.F. Geisz, D.J. Friedman, J.M. Olson, S.R. Kurtz, C. Nauka, Phys. Rev. B 62 (2000) 4211.

J. Wagner, T. Geppert, K. Köhler, P. Ganser, M. Maier, Appl. Phys. Lett. 83 (2003) 2799.

A. Mascarenhas, M.J. Seong, S. Yoon, J.C. Verley, J.F. Geisz, M.C. Hanna, Phys. Rev. B 68 (2003) 233201.

T. Geppert, J. Wagner, K. Köhler, P. Ganser, M. Maier, Appl. Phys. Lett. 80 (2002) 2081.

S. Lazić, J.M. Calleja, R. Hey, K. Ploog, Mater. Sci. Forum 518 (2006) 17-22.

S. Lazić, J.M. Calleja, R. Hey, K. Ploog, Phys. Status Solidi (b) 243 (2006) 1634.

R. Hey, Y.J. Han, M. Giehler, M. Ramsteiner, H.T. Grahn, K.H. Ploog, J. Crystal Growth 278 (2005) 219.

A.M. Teweldeberhan, S. Fahy, Phys. Rev. B 72 (2005) 195203.

A.M. Teweldeberhan, S. Fahy, Phys. Rev. B 73 (2006) 245215.

Z.C. Feng, S. Perkowitz, D.K. Kinell, R.L. Whitney, D.N. Talwar, Phys. Rev. B 47 (1993) 13466. 